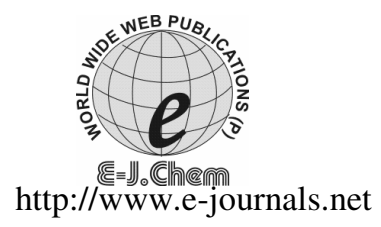

ISSN: 0973-4945; CODEN ECJHAO

E-Journal of Chemistry

2009, 6(S1), S329-S341

\title{
Chemical Studies on the Removal of Iron from Crude Phosphoric Acid Using an Organosilicon Compound
}

\author{
M H. SOLIMAN ${ }^{*}$, H S.GADO ${ }^{\S}$ and M N. KOURAIM ${ }^{\S}$ \\ *Chemistry Department, \\ Faculty of Science, Helwan University, Helwan, Egypt. \\ ${ }^{\S}$ Nuclear Materials Authority. P.O. Box 530, El Maddi, Cairo, Egypt. \\ drmadihahasn@yahoo.com
}

Received 28 April 2009; Accepted 6 June 2009

\begin{abstract}
A new adsorbent has been developed to reduce the concentration of iron in crude Egyptian phosphoric acid. This adsorbent has been formed by the treatment of silicate compound derived from clay mineral with $\pi$ organic acceptor ligand to carry out the exchange of ions as well as complexation with iron. Several parameters (shaking time, temperature, sorbent mass, and batch factor) have been studied. The adsorption of iron from crude phosphoric acid was investigated. The various methods to characterize the adsorption of iron on organosilicon compound (OSC) were collectively evaluated in this study. According to the Langmiur model, the maximum monomolecular capacity $\left(\mathrm{Q}_{0}\right)$ is $122 \mathrm{mg} / \mathrm{g}$ and $122 \mathrm{mg} / \mathrm{g}$ with Freundlich model for an initial iron concentration of $2.37 \%$ contained in crude phosphoric acid. Characterization studies such as $\mathrm{x}$-ray diffraction, infrared spectroscopy and electron scanning microscope were investigated to substantiate the nature of iron-OSC complexes.
\end{abstract}

Keywords: Chemical studies, Organosilicon compound, Crude phosphoric acid and Adsorption.

\section{Introduction}

The wet-process involves reaction of phosphate rock with an acid (mainly sulfuric acid) to produce crude phosphoric acid which contains a variety of impurities, that vary according to the original of minerals. Many of these impurities particularly the solid ores are removed from the acid by techniques such as clarification. The presence of these impurities affects the quantity and the quality of the product. For this reason, about $95 \%$ of the acid produced by the wet-process is directly used as fertilizers and excluded from the use in non-fertilizer applications ${ }^{1}$. Many research techniques have been investigated for purifying phosphoric acid, such as: liquid-liquid extraction ${ }^{2-9}$, solid-liquid extraction ${ }^{10}$, crystallization, concentration or 
addition of additives ${ }^{11}$ and by membrane process ${ }^{12}$.The use of these techniques were limited due to a number of disadvantages such as: i) limited efficiency; ii) high costs of organic solvents and resins (more often not regenerable); iii) difficulty in recovering all the solvent from both the raffinate and the purified acid, due to its granular structure, insolubility in acids, chemical stability, high mechanical strength, and its local availability at almost low cost. The advantages in the application of organosilicon compound (OSC) are: i) no need to regenerate them; ii) their low production costs and waste minimization. In this work, a new material is proposed to achieve the reduction of iron impurities from Egyptian crude phosphoric acid $\left(\mathrm{P}_{2} \mathrm{O}_{5}=40.2 \%\right)$. The initial concentration of iron in crude phosphoric acid was $2.37 \%$. This technique is based on the adsorption of iron on the surface of the OSC. In this study, factors affecting the sorption process are investigated in the mode operation of batch process.

\section{Experimental}

The starting material for this work is a commercial wet-process phosphoric acid $\left(\mathrm{P}_{2} \mathrm{O}_{5}=40.2 \%\right)$, which is kindly supplied by Abu-Zaabal Company, Cairo, Egypt. Some characteristics of the acid are given in Tables $1 \& 2$.

Table 1. Physical characteristics of the crude phosphoric acid.

\begin{tabular}{cc}
\hline Character & Value \\
\hline Optical density (Absorbance) & 1.4 \\
PH & 0.6 \\
Density & $1.54 \mathrm{~kg} / \mathrm{L}$ \\
Viscosity & $13.6 \mathrm{CP}$ \\
Electromotive force & $450 \mathrm{mv}$ \\
Total solids & $2 \%$ \\
\hline
\end{tabular}

Table 2. Chemical properties of the crude phosphoric acid.

\begin{tabular}{|c|c|c|c|}
\hline Component & Value, $\%$ & Component & Value, ppm \\
\hline $\mathrm{P}_{2} \mathrm{O}_{5}$ & 40 & $\mathrm{Cd}$ & 15 \\
\hline $\mathrm{Fe}_{2} \mathrm{O}_{3}$ & 2.2 & $\mathrm{Co}$ & 40 \\
\hline $\mathrm{Al}_{2} \mathrm{O}_{3}$ & 0.66 & $\mathrm{Cr}$ & 120 \\
\hline $\mathrm{SiO}_{2}$ & 0.98 & $\mathrm{Ni}$ & 42 \\
\hline $\mathrm{F}$ & 0.85 & $\mathrm{~Pb}$ & 20 \\
\hline $\mathrm{MgO}$ & 0.5 & $\mathrm{Zn}$ & 200 \\
\hline $\mathrm{CaO}$ & 0.3 & $\mathrm{~V}$ & 35 \\
\hline $\mathrm{SO}_{4}$ & 1.3 & As & 7 \\
\hline $\mathrm{FeO}$ & 0.19 & $\mathrm{Mn}$ & 800 \\
\hline Total $\mathrm{Fe}$ as $\mathrm{Fe}_{2} \mathrm{O}_{3}$ & 2.37 & $\mathrm{Na}_{2} \mathrm{O}$ & 450 \\
\hline Organic matter & 0.51 & $\mathrm{~K}_{2} \mathrm{O}$ & 200 \\
\hline $\mathrm{U}$ & $55(\mathrm{ppm})$ & & \\
\hline
\end{tabular}

\section{Preparation of OSC}

Organosilicon compound was prepared by the following procedure. The silicon compound was derived from clay minerals using caustic soda and potassium thiosulfate with ratio $3: 1: 1.5$ w/w. Potassium thiosulfate used as initiator for the polymerization of silicate. $2.5 \mathrm{~g}$ of the derived silicon mixed with $1 \mathrm{~g}$ of acetyl trimethyl ammonium bromide as inert electrolyte for enhancement of the adsorption process, in addition to $3 \mathrm{~g}$ of $\mathrm{NaOH}$ in $30 \mathrm{~mL}$ of water. 
The mixtures were shaked vigorously with 0.01 molar of a $\pi$ acceptor ligand. The organosilicon compound obtained was washed several times with distilled water until $\mathrm{pH}$ becomes neutral. Some characteristics of the silicate compounds, OSC before and after adsorption of iron are given in Table 3. The $\pi$ acceptor ligand is a poly dentate ligand which contains mainly thio, cyano and carboxylic ester groups as shown in IR spectrum. The reagents used in the chemical analysis are of analytical grade. Double distilled water was used in all preparations.

Table 3. Chemical composition of silicate compound, OSC before and after adsorption of iron

\begin{tabular}{cccc}
\hline OSC after & OSC before & Silicate compound & Component \\
\hline 31.76 & 64.63 & 61.65 & $\mathrm{SiO}_{2}$ \\
0.53 & 0.41 & 1.02 & $\mathrm{TiO}_{2}$ \\
13.75 & 19 & 26 & $\mathrm{Al}_{2} \mathrm{O}_{3}$ \\
48.36 & 1.5 & 6.74 & $\mathrm{Fe}_{2} \mathrm{O}_{3}$ \\
0.51 & 0.27 & 0.59 & $\mathrm{CaO}$ \\
0.44 & 12 & 0.75 & $\mathrm{~K}_{2} \mathrm{O}$ \\
0.34 & 0.36 & 1.22 & $\mathrm{SO}_{3}$ \\
3 & 1.21 & 2.12 & $\mathrm{MgO}$ \\
98.69 & 99.38 & 100 & Total \\
\hline
\end{tabular}

\section{Spectrophotometric determination of iron}

Iron was determined spectrophotometrically by complexation with 1,10 phenanthroline in the presence of hydroxylamine hydrochloride and in the presence of sodium acetate as a buffer solution as follows. In a $25 \mathrm{~mL}$ measuring flask to a micro sample containing iron, $2 \mathrm{~mL}$ of $10 \%$ hydroxylamine hydrochloride, $4 \mathrm{~mL}$ of sodium acetate $(10 \%)$ and $5 \mathrm{~mL}$ of 1.10 phenanthroline was added to the mark and dissolved with distilled water. The absorbance was then measured at $512 \mathrm{~nm}$ using all constituents without iron as blank solution $^{13}$.

\section{Qualitative analysis of OSC before and after adsorption of iron}

Identification of the OSC before and after adsorption of iron was carried out using the infrared (IR) recording spectrometer. To accomplish this, one mg of OSC before and after adsorption of iron was mixed with $200 \mathrm{mg}$ of dried $\mathrm{KBr}$. Compression disk was then made by compressing the mixture for $5 \mathrm{~min}$ at $20000 \mathrm{Lbs} / \mathrm{cm}^{2}$. Analysis of the OSC before and after adsorption of iron by electron microscope was carried out according to the following method. A small quantity of each sample was shaken in a test tube with distilled water to obtain a suspension. A drop of this suspension was placed on a coated microscope slide. A further drop was spread on a clean glass slide and a direct platinum carbon replica formed. New tensile fracture surfaces were replaced with carbon and shadowed with gold palladium then electron microscope photos were taken.

\section{Adsorption studies}

In the present work the adsorption system was studied by batch process. The factors affecting the adsorption process, e.g. shaking time, batch factor, sorbent mass and temperature were studied. In all cases $10 \mathrm{~mL}$ of the crude acid was contacted with known weights of the adsorbate in a stoppered glass bottles. The conditions of each experiment were adjusted and the bottles were shaken using a thermostatic shaker to achieve equilibrium concentration. Each mixture was filtered and the samples were analyzed for organic matter and iron using UV-Vis spectrophotometer. The Langmuir isotherm is represented by the following equation:

$$
1 / \mathrm{q}_{\mathrm{e}}=\left(1 / \mathrm{q}^{\mathrm{o}}\right)+(1 / \mathrm{bq})\left(1 / \mathrm{C}_{\mathrm{e}}\right)
$$


Where $C_{\mathrm{e}}$ is the equilibrium concentration $(\mathrm{mg} / \mathrm{L}), \mathrm{q}_{\mathrm{e}}$ is the amount adsorbed at equilibrium time (mg/g) and $q^{\circ}$ and $b$ are Langmuir constants related to adsorption capacity and energy of adsorption, respectively. These can be calculated from the $1 / \mathrm{q}_{\mathrm{e}} v s .1 / \mathrm{C}_{\mathrm{e}}$ plot by the relationships: $q^{\circ}=$ intercept $^{-1}$ and $b=$ slope $^{-1} \times$ intercept. The favorable nature of adsorption can be expressed in terms of a dimensionless separation factor of equilibrium parameter, which is defined by:

$$
\mathrm{RL}=1 /\left(1+\mathrm{bC}_{\mathrm{o}}\right)
$$

Where, $\mathrm{b}$ is the Langmuir constant and $C_{\mathrm{o}}$ is the initial concentration of the adsorbate in solution.

Freundlich equation is presented as:

Rearranging gives:

$$
\mathrm{q}_{\mathrm{e}}=\mathrm{K}_{\mathrm{f}} \mathrm{C}_{\mathrm{e}}{ }^{1 / \mathrm{n}}
$$

$$
\log \mathrm{q}_{\mathrm{e}}=\log \mathrm{K}_{\mathrm{f}}+1 / \mathrm{n} \log \mathrm{C}_{\mathrm{e}}
$$

Hence, a plot of $\log \mathrm{q}_{\mathrm{e}} v s . \log \mathrm{C}_{\mathrm{e}}$ enables the constant $K_{\mathrm{f}}$ and exponent 'n' to be determined.

\section{Batch experiments}

The factors affecting the adsorption process, e.g. shaking time, batch factor and sorbent mass were studied. In all cases, $10 \mathrm{~mL}$ of green acid was contacted with fixed amount of OSC in stoppered glass bottles. The conditions of each experiment were adjusted and the bottles were shaken using a thermostatic shaker to achieve equilibrium concentration. Each mixture was filtered and the samples were analysed for iron using a Shimadzu model $160 \mathrm{~A}$ double-beam UV spectrophotometer. Matched $10 \mathrm{~mm}$ quartz absorption cells were used. In all cases, the difference between the initial concentration $\left(C_{\mathrm{o}}\right)$ and the equilibrium concentration $\left(C_{\mathrm{e}}\right)$ was calculated and used to determine the adsorptive capacity $\left(q_{\mathrm{e}}\right)$ as follows. $q_{\mathrm{e}}=V\left(C_{\mathrm{o}}-C_{\mathrm{e}}\right) / m$, where $V$ is the total volume of solute solution $(\mathrm{mL}) ; m$ is the mass of sorbent used $(\mathrm{g}), C_{\mathrm{o}}$ is the initial concentration of the solute $(\mathrm{mg} / \mathrm{L})$ and $C_{\mathrm{e}}$ is the residual concentration of the solute $(\mathrm{mg} / \mathrm{L})$. Adsorption isotherms of iron were determined by shaking various amounts OSC with constant volume of green acid $(10 \mathrm{~mL})$ until equilibrium is reached. The residual concentration was determined as described above.

\section{Results and Discussion}

\section{Effect of OSC dose}

Different weights of OSC were used at $25^{\circ} \mathrm{C}$. The OSC dose used covers the range from 0.5 to $12 \mathrm{~g} / \mathrm{L}$. The uptake percent of iron on the OSC plotted against the respective OSC dose in Figure 1 shows that the adsorption increases by increasing OSC dose till $12 \mathrm{~g} / \mathrm{L}$ then become a constant because of the saturation of the active sits.

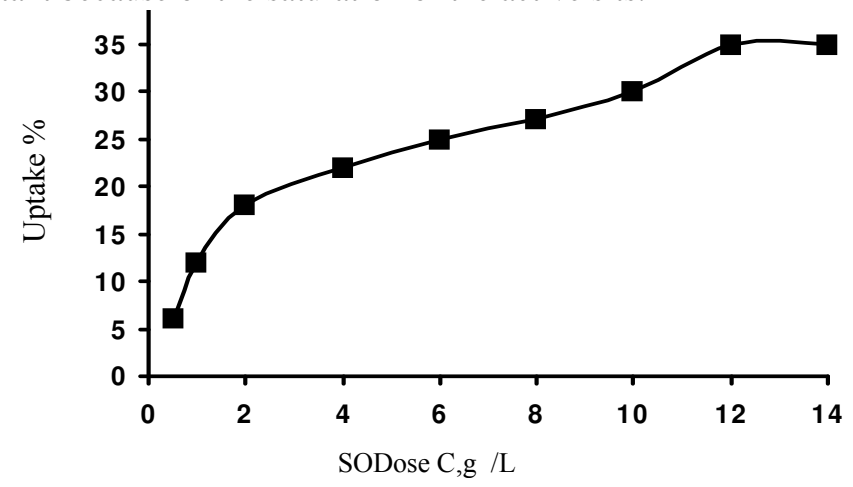

Figure 1. Effect of OSC dose on uptake \% of iron. 


\section{Effect of shaking time}

Different shaking time intervals were studied in the range of (5-40) min., to study the uptake $\%$ of iron by OSC the results are represented in Figure 2. The results show that equilibrium is reached after $15 \mathrm{~min}$. of shaking time.

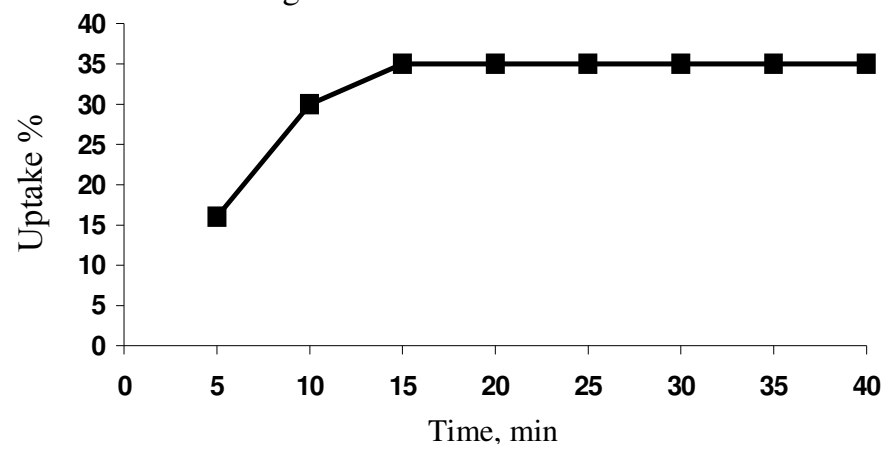

Figure 2. Effect of contact time on uptake \% of iron by OSC.

\section{Effect of temperature}

The effect of temperature on the adsorption of iron by OSC was studied by varying the temperature in the range $30-70{ }^{\circ} \mathrm{C}$. Plotting of uptake \% values against the respective absolute temperature in Figure 3, confirm that the adsorption of iron on OSC may be chemical in nature where, the adsorption rate is improved when temperature increases.

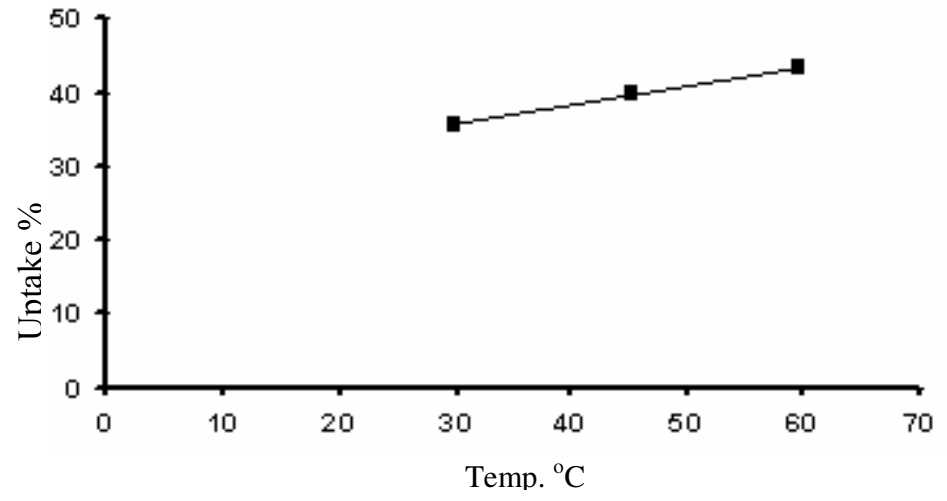

Figure 3. Effect of temperature on uptake \% of iron by OSC.

\section{Effect of $\mathrm{H}_{3} \mathrm{PO}_{4}$ volume to $\mathrm{OSC}$ mass ratio $(\mathrm{v} / \mathrm{m})$}

The effect of changing $\mathrm{v} / \mathrm{m}$ ratio studied by increasing the weight of sorbent in the range 0.5 $12 \mathrm{~g}$, while fixing the volume at $1 \mathrm{~L}$. From the results shown in Figure 4, it was deduced that as $\mathrm{v} / \mathrm{m}$ ratio decreases by increasing the sorbent weight the uptake percent increases. This may be related to the increase of sorbent of iron due to the increase of the available sites of sorbent.

\section{Effect of organic matter concentration}

The effect of organic matter impurities concentration in the crude phosphoric acid on the uptake of iron was studied by using two different concentrations of organic matter. From the data obtained it was found that the organic matter originally present in the crude phosphoric acid have no significant effect on the adsorption of iron by OSC. 


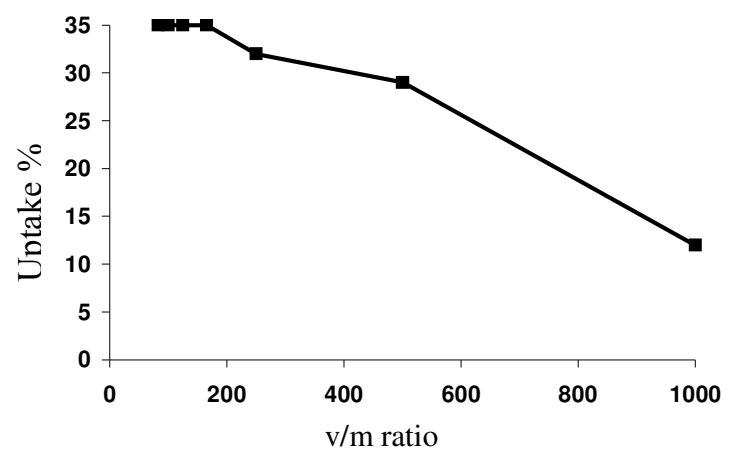

Figure 4. Effect of $\mathrm{v} / \mathrm{m}$ ration on uptake $\%$ of iron by OSC.

\section{Effect of the oxidation state of iron}

The effect of iron oxidation state on its uptake $\%$ by OSC is studied. The results in Figure 5 show that ferrous ions are adsorbed more than ferric ions. This could be explained by the presence of the $\pi$ acceptor ligand which interact with iron via electron transfer from the ligand to ferrous ions then return back to the ligand throught $\pi$ interaction.

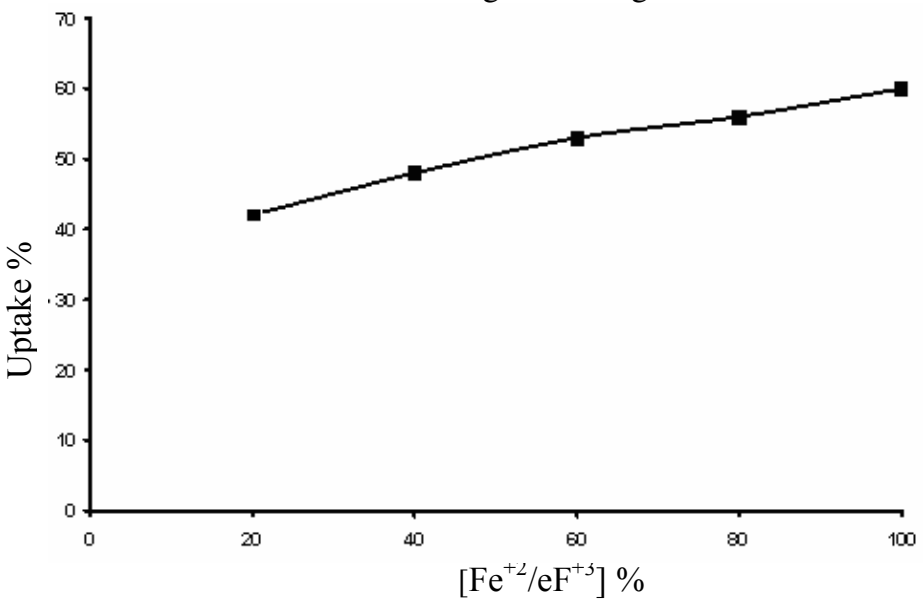

Figure 5. Effect of $\mathrm{Fe}^{2+}$ to $\mathrm{Fe}^{3+}$ percentage in uptake \%.

\section{Adsorption isotherms}

Adsorption data for a wide range of adsorbate concentrations are most conveniently described by adsorption isotherm, which relate adsorption density $\mathrm{q}_{\mathrm{e}}$ to equilibrium adsorbate concentration in the bulk fluid phase, $\mathrm{C}_{\mathrm{e}}$ as shown in Figure 6 . The Langmuir isotherm $^{14}$ was tested by plotting $1 / \mathrm{C}_{\mathrm{e}} v s .1 / \mathrm{q}_{\mathrm{e}}$ where, $\mathrm{C}_{\mathrm{e}}(\mathrm{g} / \mathrm{L})$ is the equilibrium concentration of the investigated metal ion, $\mathrm{q}_{\mathrm{e}}(\mathrm{g} / \mathrm{g})$ is the metal ion concentration in the loaded solid phase as shown in Figure 7. The obtained linear relation indicates that the adsorption of iron obey langmuir isotherm. From the figure, $\mathrm{q}$ max for iron was found to be $122.46 \mathrm{mg}$ iron / $\mathrm{g}$ OSC.and (b) for iron was 0.18 Freundlich isotherm ${ }^{15}$ is also tested by drawing a plot of $\log \mathrm{q}_{\mathrm{e}} v s \log \mathrm{C}_{\mathrm{e}}$ as shown in Figure 8. The adsorption of iron was found to follow the Freundlich isotherm. The fitting of the data to Freundlich isotherm suggests that adsorption is not restricted to one specific class of sites and assumes surface heterogeneity. From the slope and intercept of the plot, the Freundlich parameters are calculated, 


$$
\begin{aligned}
\mathrm{K} & =122.46 \mathrm{mg} / \mathrm{g} \text { sorbent. } \\
1 / \mathrm{n} & =5.59 \\
\text { and } \mathrm{n} & =0.18
\end{aligned}
$$

The slope of Freundlich isotherm is more than 1, indicating a concentration independent adsorption of iron ${ }^{3}$.

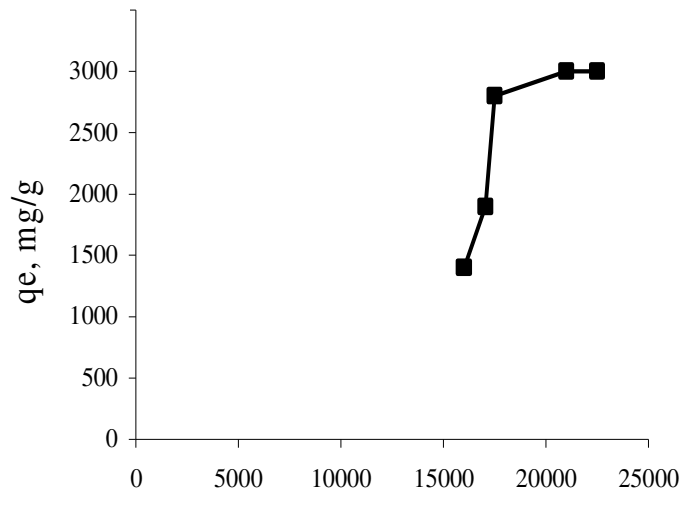

$\mathrm{Ce}, \mathrm{mg} / \mathrm{L}$

Figure 6. General adsorption isotherm of iron by OSC.

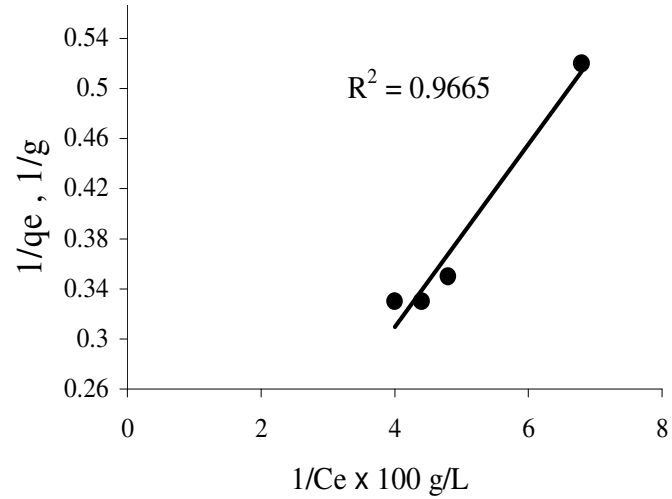

Figure 7. Langmuir adsorption isotherm of iron by OSC.

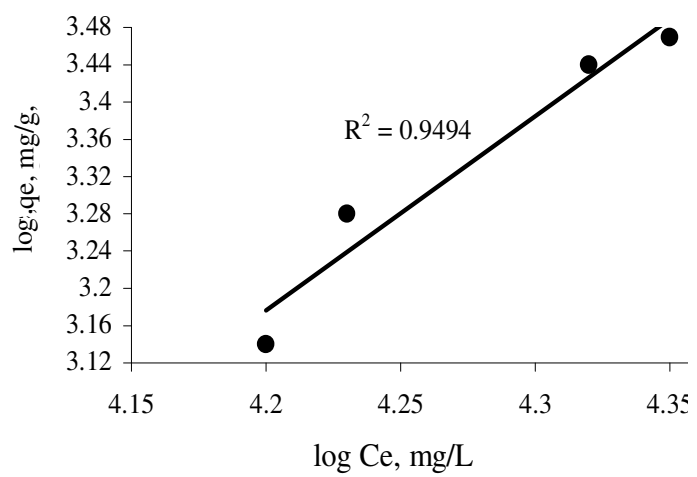

Figure 8. Freundlich adsorption isotherm of iron by OSC. 


\section{Sorption mechanism}

Sorption of iron onto OSC can be understood in terms of hydrophilic surface containing mainly $\mathrm{K}$ which works as ion exchanger for $\mathrm{K}$ ions and complex formation with deprotonated sulfide groups as a ligand ${ }^{16}$ as well as cyanide group coordinated with iron via charge transfer from iron to the $\pi$ molecular orbital of cyanide group. Uptake of iron was shown to be accompanied by a stoichiometric replacement of $\mathrm{K}$ from the exchange sites $^{17,18}$. To substantiate the nature of OSC iron complexes, classical x-ray diffractometry, in conjunction with and complementary with infrared spectroscopy are investigated. Also electron scanning microscope is singularly suited for the study of OSCiron interactions.

\section{$X$-ray studies}

$\mathrm{X}$-ray diffractometry is one of the major tools in the study of metal complexes. Its usefulness is due to the relative ease with which one can determine whether adsorption only occurs on external mineral surfaces, or if the metal ions is capable of being adsorbed within the inter layer spaces. Furthermore, the orientation of the metal ion between lattice layers, whether parallel, normal or at an angle to the mineral plane, can be predicted from basal expansion, provided that interlayer adsorption is regular X-ray diffractograms of silicate compound, OSC and iron-OSC are depicted in Figures 9, 10 \& 11 respectively. Interpretation of these diffractograms in terms of the basal spacings of OSC before and after sorption is given in Table 4. Comparison between OSC and iron-OSC complex reveals that the basal spacing of the studied OSC remains unchanged to some extent. Comparing c-spacing of OSC and their iron complexes indicates that applied treatments do not affect the characteristic diffraction peaks. These findings dictate that iron must have been adsorbed on external surfaces and edges of such material. Nevertheless, the slight contraction or expansion of c-spacing may suggest the possible entrapment of the iron species into the tunnels and channels of the OSC, which remained, more or less, unchanged. Also X-ray diffratograms of the iron-OSC shown in Figures 9 indicate the appearance of the characteristic iron peak $\left(2.0091 \mathrm{~A}^{\circ}\right)$ on the OSC after acid treatments which provide an evidence for the sorption of iron. Nevertheless, IR spectroscopy and electron microscopy will add further confirmation regarding to the type of bonding and morphology of sorbed metal ion.

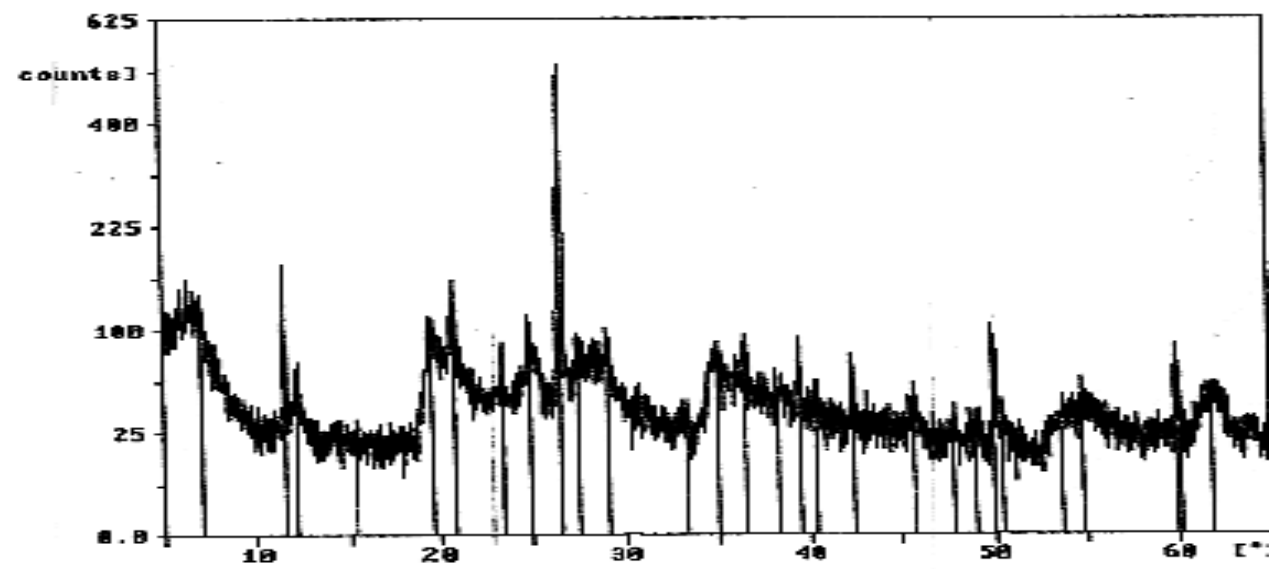

Figure 9. X-ray diffraction of silicate compound. 


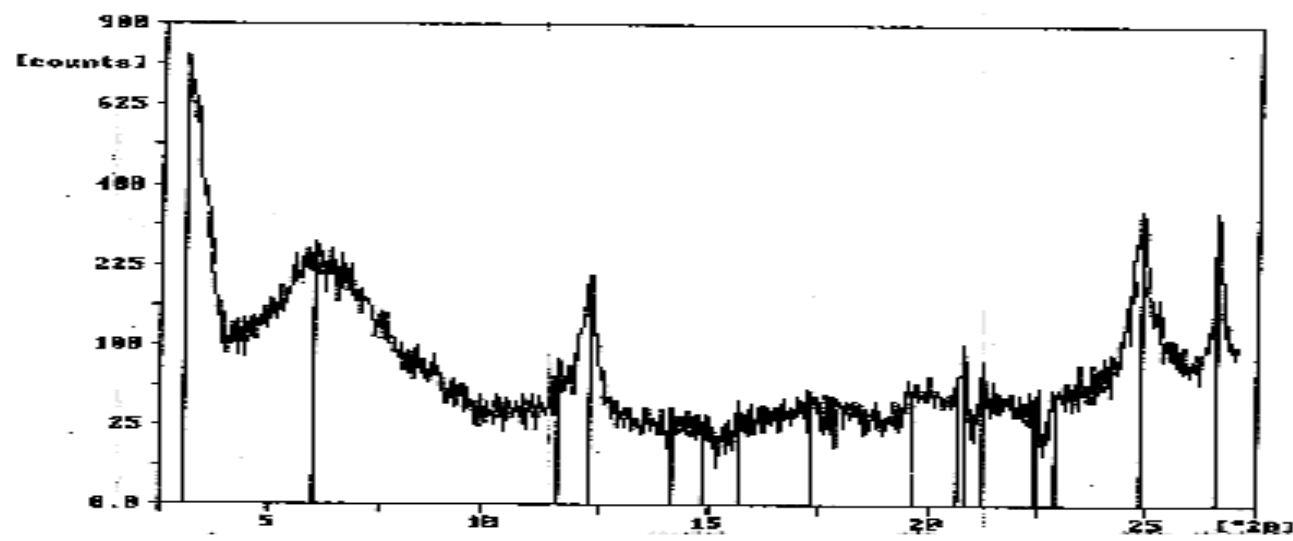

Figure 10. X-ray diffraction of OSC before adsorption.

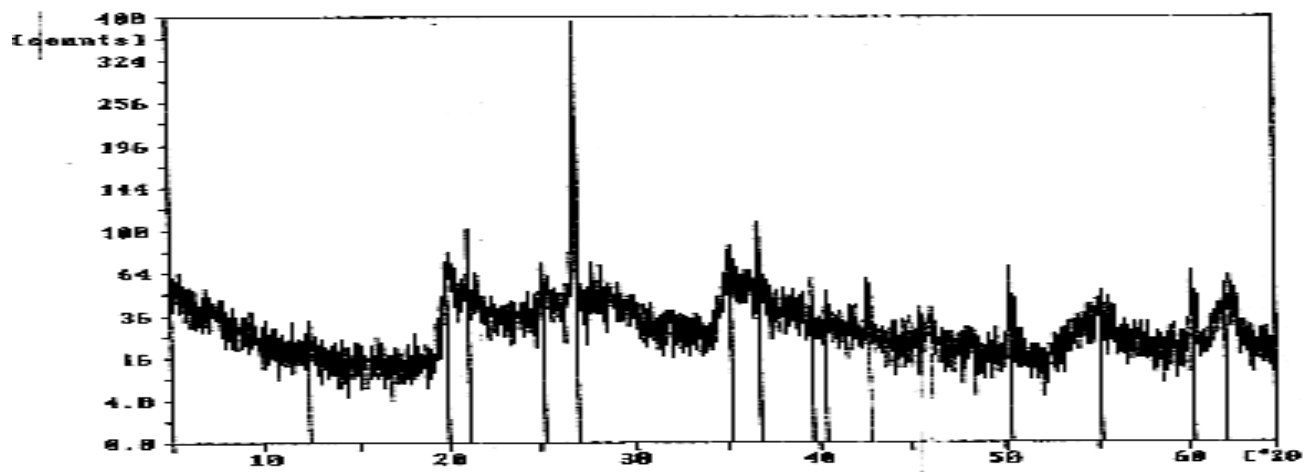

Figure 11. X-ray diffraction of OSC after adsorption.

Table 4. Basal spacing of iron-OSC complexes (bulk sample).

\begin{tabular}{cc}
\hline OSC Before & OSC After \\
\hline 5.65 & 5.73 \\
4.26 & 4.28 \\
3.35 & 3.36 \\
\hline
\end{tabular}

\section{Infrared spectroscopy studies}

The IR adsorption bands and the frequencies of vibrations are dependent on the mass of atoms, the restraining forces of the bonds and the geometry of structure. Consequently, the spectrum is sensitive to isomorphous substitutions in the mineral structures, as these affect both bond strengths and atom masses. The symmetry and regularity of structure determine the intensity and frequency of its vibrations ${ }^{19}$. So that the IR spectrum is often a sensitive indicator of the degree of order of a mineral. Therefore, IR spectrum of a mineral is a characteristic feature that permits the identification of mineral species. IR spectra can provide direct evidence on the chemical and physical processes that lead to adsorption on surface, and these reactions may, in turn, serve to differentiate the various types of surfaces present in heterogeneous systems as OSC. The IR spectrum of silicate compound shown in Figure 12 is characterized by the following absorption bands: 


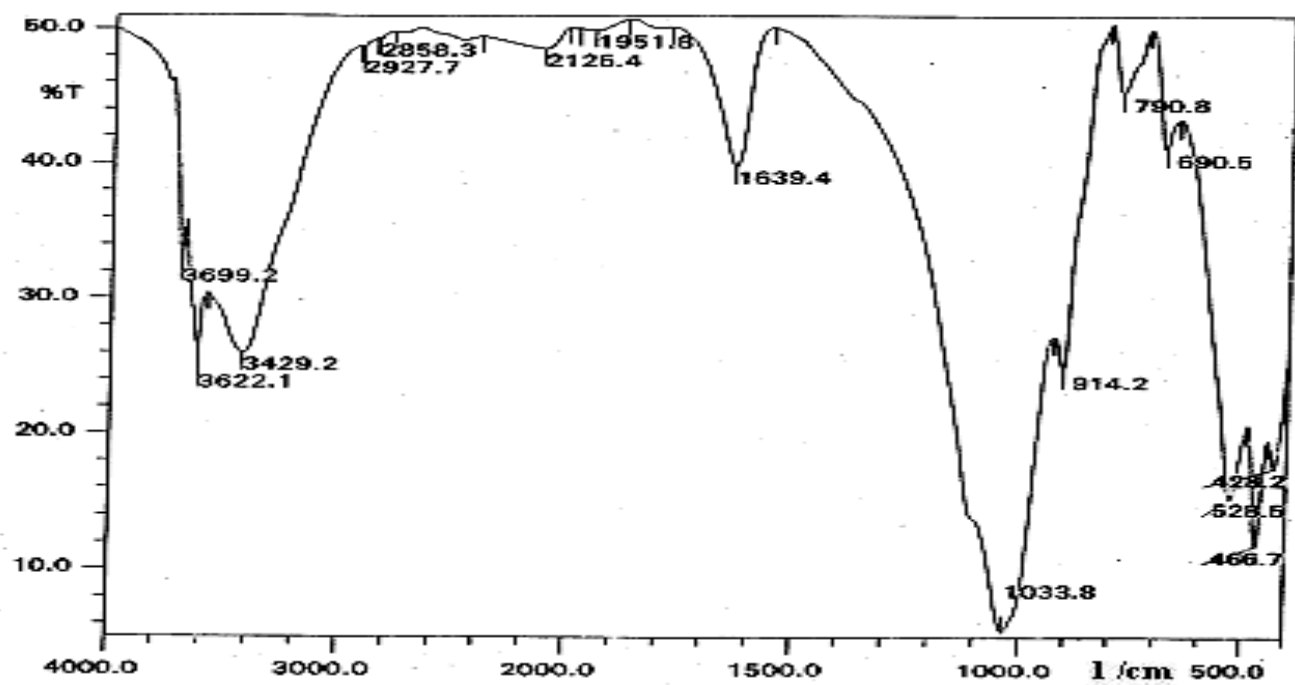

Figure 12. IR spectrum of silicate compound.

Two sharp bands at $3699 \mathrm{~cm}^{-1}$ and $3622 \mathrm{~cm}^{-1}$, indicating isomorphous substitution in the crystal lattice, the band mostly arises from $\mathrm{OH}$ coordinated to $(\mathrm{Al}, \mathrm{Fe})$ pair. A medium broad band at $3429 \mathrm{~cm}^{-1}$, indicating $\mathrm{OH}$ stretching vibrations, the broadening is a result of $\mathrm{Al}$ substitution for $\mathrm{Si}$ in the tetrahedral sheet. A medium broad band at $1635 \mathrm{~cm}^{-1}$ ascribed to deformation $\mathrm{OH}$ or absorbed water. Broad band at $1035 \mathrm{~cm}^{-1}$, mostly related to Si-tetrahedron in smectite clay minerals group. Three sharp bands at 528, 690 and $914 \mathrm{~cm}^{-1}$, due to Si-O stretching bands which are complicated by variations in $\mathrm{Al}$ substitution for $\mathrm{Si}, \mathrm{OH}$ bending vibration causes a characteristic absorption at $914 \mathrm{~cm}^{-1}$ which indicates that only $\mathrm{Al}$ is present in octahedral sheet. Two medium sharp bands at $428 \mathrm{~cm}^{-1}$ and $466 \mathrm{~cm}^{-1}$, indicting water linked to Mg ions. A strong sharp band at $790 \mathrm{~cm}^{-1}$, most probably due to Al- tetrahedron I.R. spectra of the studied OSC. minerals before and after sorption of iron are shown in Figures 13, 14.

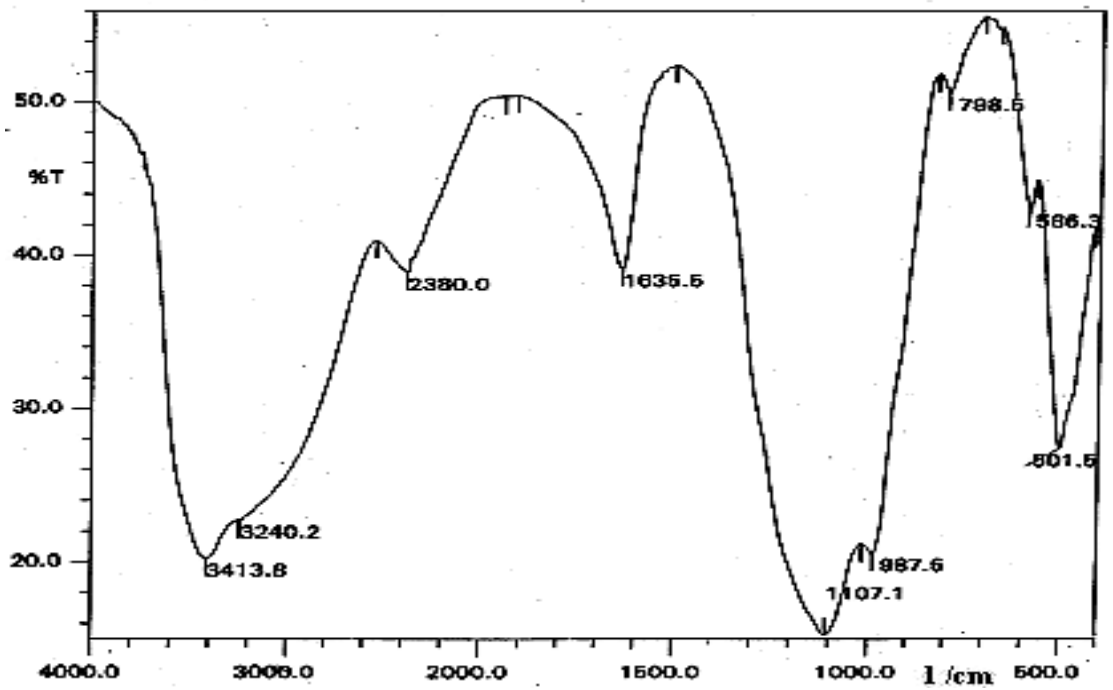

Figure 13. I.R spectrum of OSC before adsorption. 


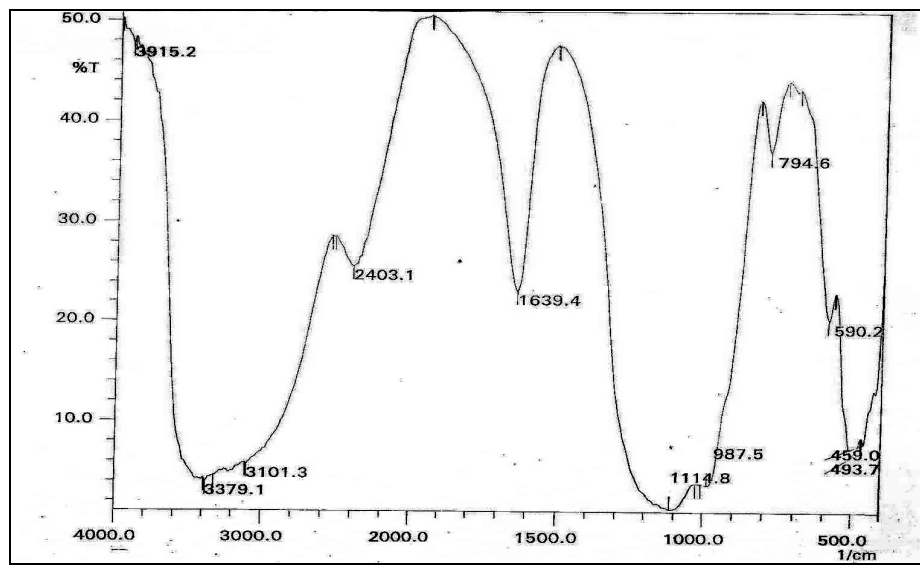

Figure 14. IR spectrum of OSC after adsorption.

\section{Spectrum of OSC before sorption}

A medium band at $1635 \mathrm{~cm}^{-1}$ ascribed to deformation $\mathrm{OH}$ or adsorbed water. Two weak bands at 501 and $586 \mathrm{~cm}^{-1}$ due to Si-O stretching bands which are complicated by variation in $\mathrm{Al}$ substitution for $\mathrm{Si}^{20}$ A strange sharp band at $798 \mathrm{~cm}^{-1}$, most probably due to $\mathrm{Al}$ tetrahedron. Weak band at $987 \mathrm{~cm}^{-1}$, mostly related to $\mathrm{C}-\mathrm{N}$ stretching vibration. A weak broad band at $1107 \mathrm{~cm}^{-1}$, ascribed to C-S stretching.

A strong broad band at 3240 and $3413 \mathrm{~cm}^{-1}$, most probably due to inter bonded $\mathrm{OH}$ stretching. A medium sharp band at $2380 \mathrm{~cm}^{-1}$, related to $\mathrm{C} \equiv \mathrm{N}$ stretching vibration.

\section{Spectrum of OSC after sorption}

To substantiate the effect of sorption on the I.R. spectra of the OSC, Figure 14 clarifies that the I.R. spectrum of iron- OSC differs from that of OSC in respect to: appearance of a new band at $459 \mathrm{~cm}^{-1}$ due to water associated with iron. Dislocation of the absorption bands at 798, 501, 586 and $1639 \mathrm{~cm}^{-1}$ to another values as they appear at 794, 493, 590 and $1635 \mathrm{~cm}^{-1}$. Dislocation of the absorption bands at 1107 and $2380 \mathrm{~cm}^{-1}$ to higher values as they appear at 1114 and 2403 $\mathrm{cm}^{-1}$ and this most probably due to the bonding between iron and the function groups corresponding to the absorption band ( $\mathrm{C}-\mathrm{S}$ and $\mathrm{C} \equiv \mathrm{N}$ respectively). Dislocation of the absorption bands 3240 and $3413 \mathrm{~cm}^{-1}$ to a tower values as they appear at 3101 and $3379 \mathrm{~cm}^{-1}$ mostly due to water linked to iron and /or hydroxyl stretching vibrations. The relative intensity of some absorption bands is some what affected. For instance, the band at $1635 \mathrm{~cm}^{-1}$ displays apparent increase in its intensity. This behavior may be taken as an indication that iron is adsorbed on the external surface of these materials and its hydration shell contribute to such absorption band.

\section{Electron Microscope studies}

The above mentioned results of X-ray and I.R. spectrum of OSC and iron-OSC complex are supported by the electron micro graphs which reveals that the silicate compound is characterized by the platy morphology and relatively fine particle size, Photographing the OSC and OSC-iron complex in the electron microscope, showed the characteristic shapes of its grains in a very clear manner. Moreover the electron micro graphs reveal that the used OSC samples have heterogeneous surface. The electron micrographs of OSC-iron complex show that an aggregate mass that appears interwoven characterized by porous structure. The varieties identified in the micrographs are small and large pores. The small variety $(\approx 1 \mathrm{~nm})$ may contain more iron. Also, the complementary EDAX technique shows the silicate compound and OSC before and after adsorption of iron as shown in Figures 15, 16 \& 17. 


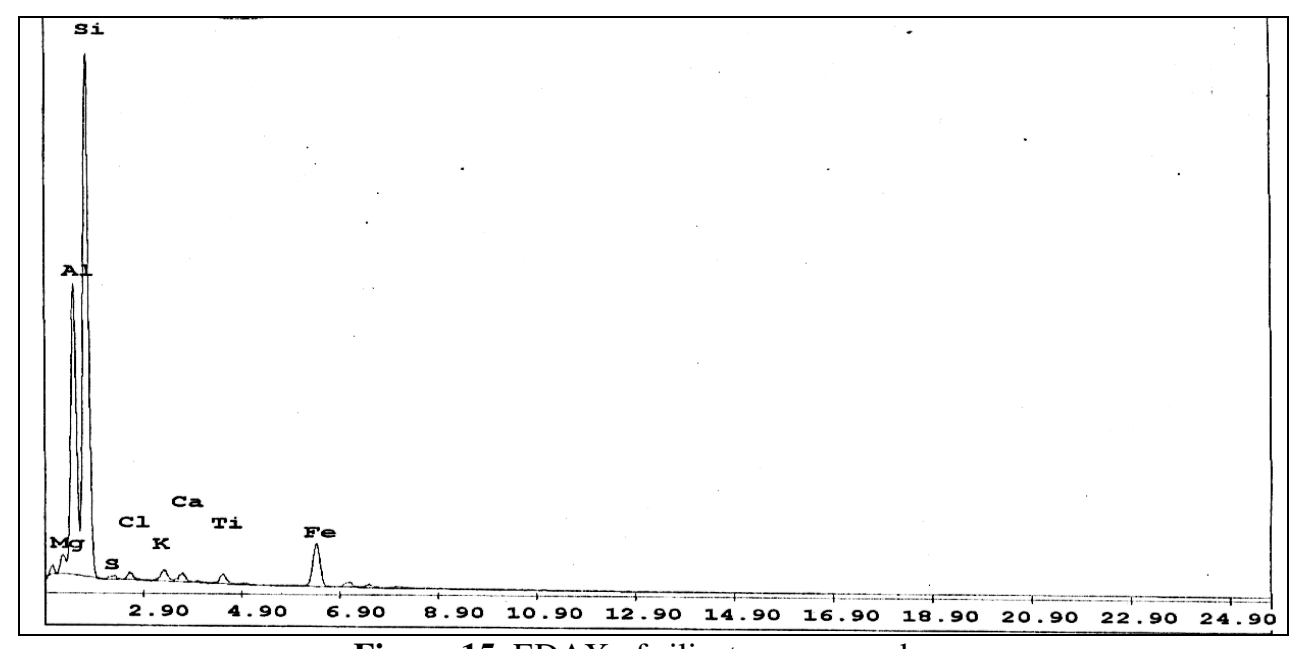

Figure 15. EDAX of silicate compounds.

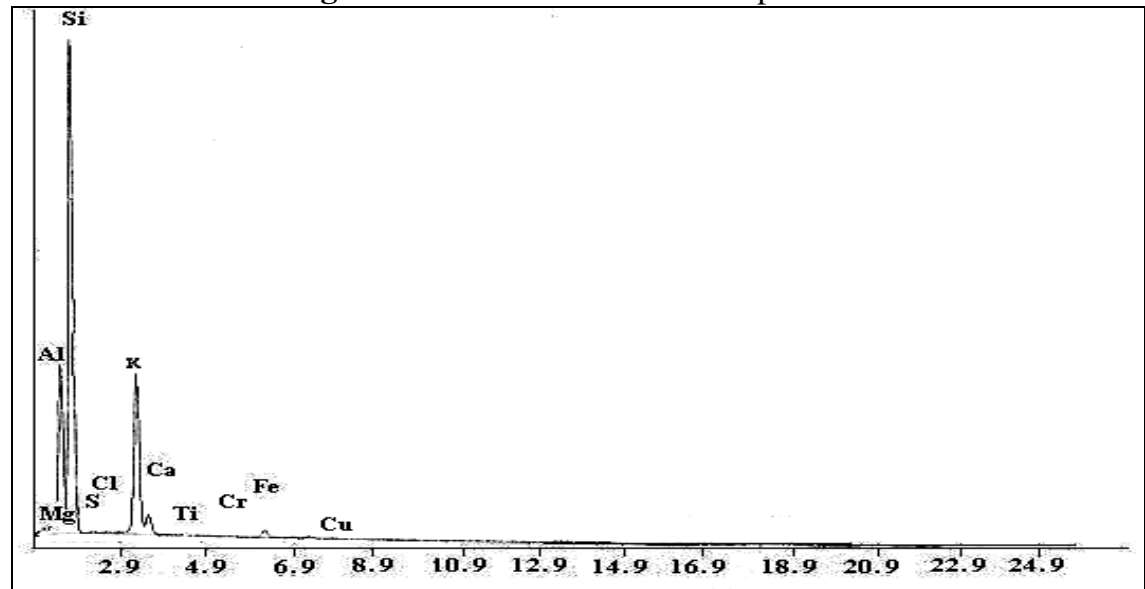

Figure 16. EDAX of OSC before adsorption.

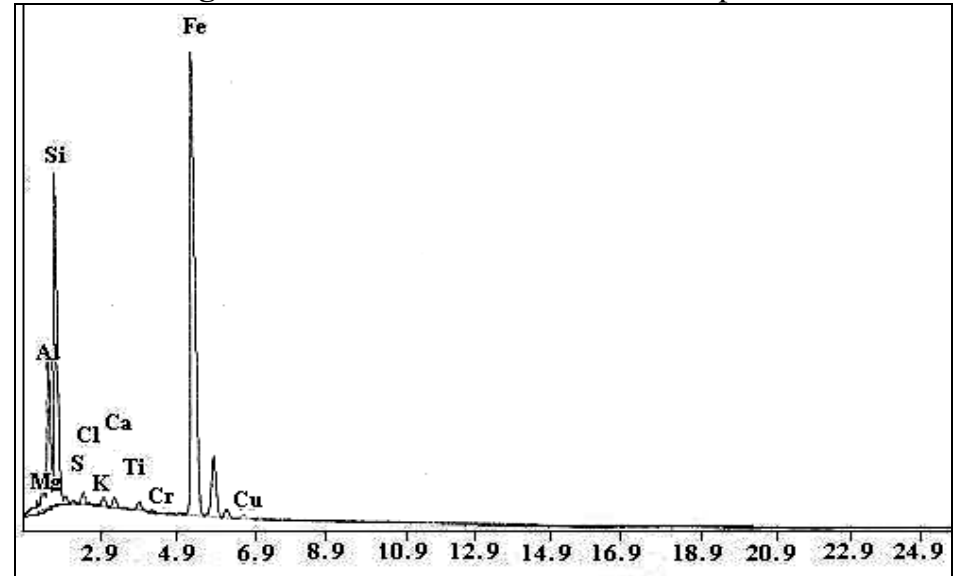

Figure 17. EDAX of OSC after adsorption. 


\section{Conclusions}

Iron could be removed efficiently from phosphoric acid produced at Abu-Zaabal Company, Egypt, using organosilicon compound. The uptake of iron increases in reducing conditions. $12 \mathrm{~g}$ of OSC is optimal for the removal of about $60 \%$ of iron content of the acid. Optimization studies with separating funnel indicate that a time of $15 \mathrm{~min}$ is sufficient for reaching equilibrium. The uptake of iron is an endothermic process.

\section{References}

$1 \quad$ Harvinderpal S L and Mishra R V, Hydrometallurgy, 2004, 73, 63.

2 Awwad N S, El-Reefy S A and Aly H F Proc. $6^{\text {th }}$ Arab Conf Peac Uses Atomic Energy, Cairo, Egypt, 14 December, 2002.

3 El-Reefy S A and Awwad N S Arab, J Nucl Sci Appl., 1997, 30, 281.

4 El-Reefy SA, Awwad NS and Aly H F, J Chem Tech Biotechnol., 1997, 69, 271.

5 Awwad N S, El-Reefy S A and Aly H F, Int Eighth Conf of Nucl Sci Appl., Cairo, Egypt, 7-12 February, 2004.

6 Ahmed H, Diamonta H, Chaker C and Abdelhamid R, Sep Purif Technol., 2007, 55, 212.

7 Glauco C D, Jose W S, Jo D and Julio C A, Minerals Engineering, 2008, 21, 416.

8 Beata P, Wladyslaw W, Michal J W, Physicochemical Problems of Mineral Processing, 2005, 39, 89.

9 Hannachi A, Habaili D, Chtara C and Ratel A, Sep Purif Technol., 2007, 55, 212.

10 Daifullah A A M, Awwad N S and El-Reefy S A, Chem Eng Process, 2004, 43, 193.

11 Mohammed K and Hussein K, Hydrometallurgy, 2000, 58, 215.

12 Myriam B C, Mohamed B A and Gerald P, Sep Purif Technol., 2006, 51, 285.

13 Marczenko Z, Spectrophotometric Determination of the Elements Wiley, New York, 1986.

14 Langmuir I., J Am Chem Soc., 1918, 40,1361.

15 Freundlich H, Methuen and Co Ltd., London, 1926.

16 El-Kamash A M, El-Sayed A A and Aly H F, J Radioanal Nucl Chem., 2002, 253, 489.

17 Abdel Aal EA, Ibrahim I, Mahmoud, M H H, El-Barbary T A and Ismail A K, Miner Metall., 1999, 16, 3.

18 Schindler P W, Fürst B, Dick R and Wolf P U, J Colloid and Interface Science, 1976, 55, 469.

19 Nyquist R A, Putzig C L and Leugers M A, Infrared Spectra, Academic Press, UK, 1977.

20 White J L, Soil Sci., 1971, 112, 22. 


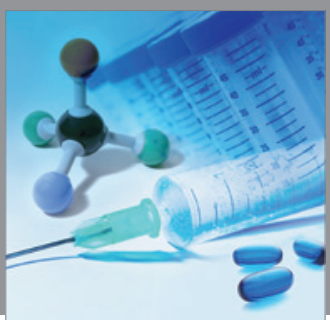

International Journal of

Medicinal Chemistry

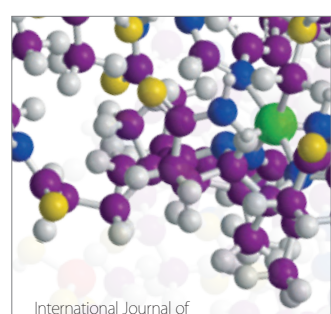

Carbohydrate Chemistry

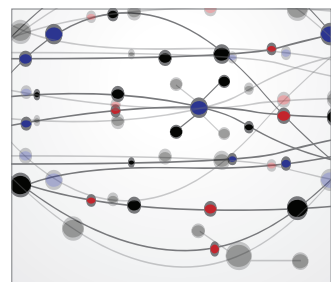

The Scientific World Journal
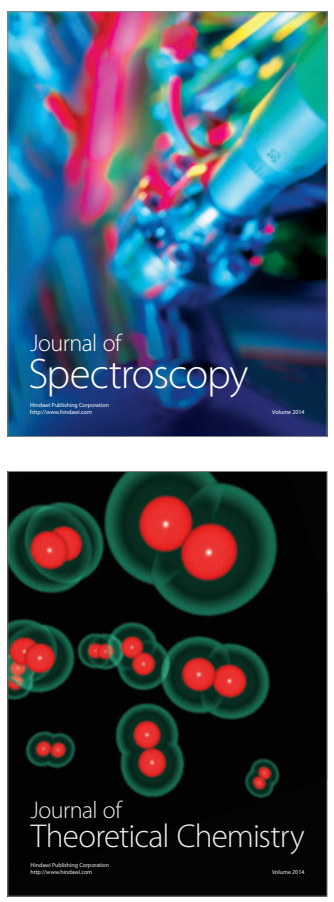
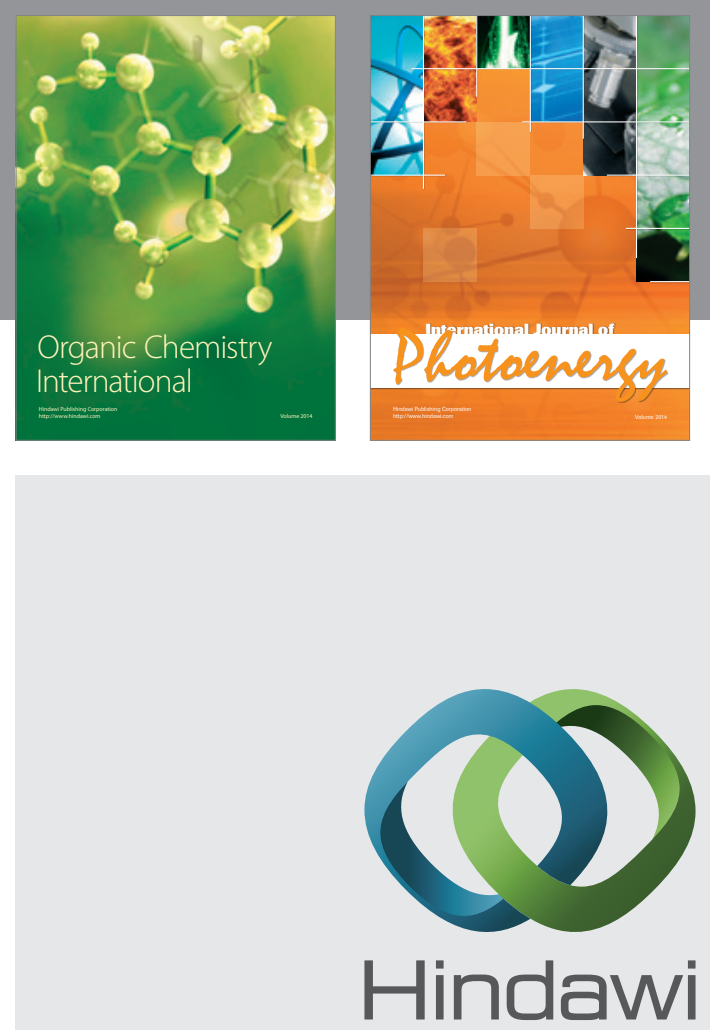

Submit your manuscripts at

http://www.hindawi.com
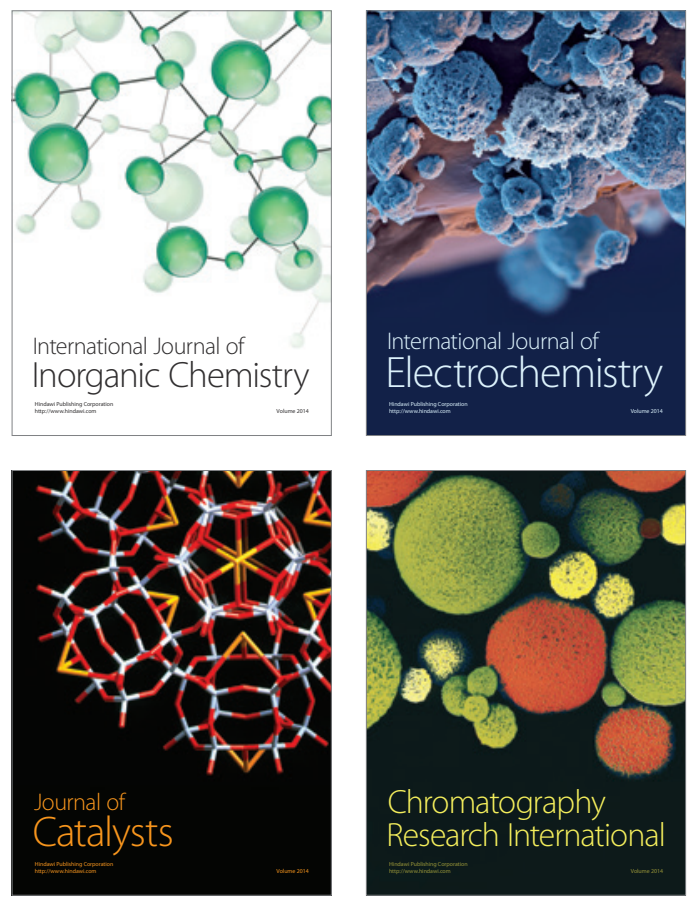
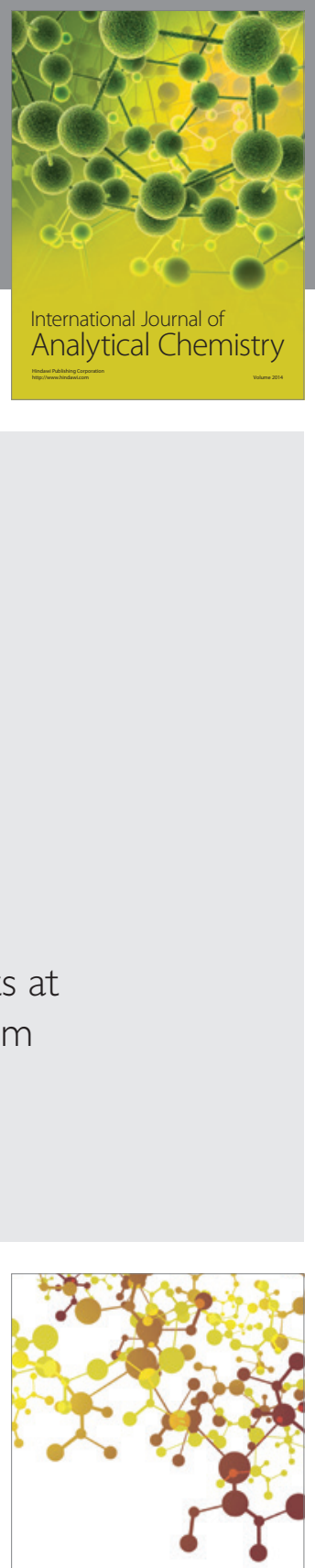

Journal of

Applied Chemistry
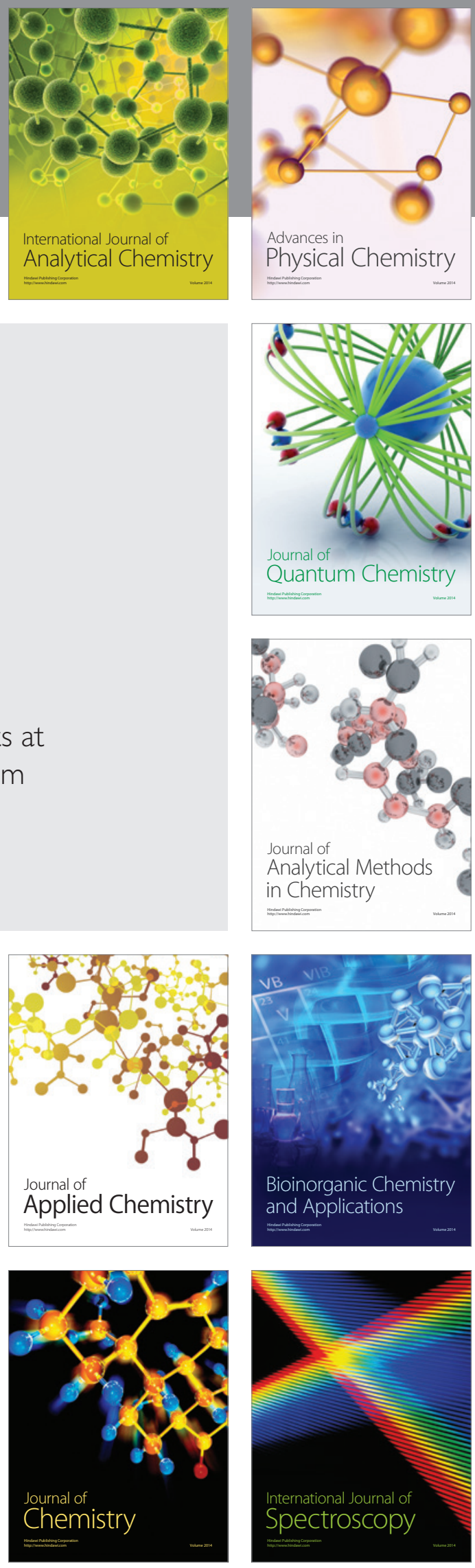